\title{
REVIEW
}

\section{Pathological demand avoidance syndrome: a necessary distinction within the pervasive developmental disorders}

\author{
E Newson, K Le Maréchal, C David
}

Arch Dis Child 2003;88:595-600

A proposal is made to recognise pathological demand avoidance syndrome (PDA) as a separate entity within the pervasive developmental disorders, instead of being classed under "pervasive developmental disorder not otherwise specified" (PDDnos, DSM-IV). ${ }^{10}$ Discriminant functions analysis shows PDA to be significantly different on many counts from classic autism and Asperger's syndrome, both separately and together, including an equal sex ratio (150 cases). Demand avoidance using social manipulation is seen in all children, which strongly contrasts with the features of autistic spectrum disorders. A criterial structure is described, supported by statistical data from a random sample of 50 children diagnosed with PDA, together with a follow up sample of 18 young adults.

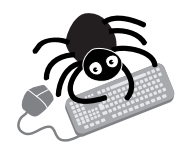

Additional information is available on the ADC website (www.archdischild.com/ supplemental)
See end of article for authors' affiliations

Correspondence to: Professor E Newson, Early Years Diagnostic Centre, 272 Longdale Lane, Ravenshead, Nottingham NG15 9AH, UK: diagnostic-centre@ sutherlandhouse.org.uk

Accepted 16 February 2003
$\mathrm{F}$ or the diagnostician specialising in the pervasive developmental disorders, there is a responsibility to fit the diagnosis to the child in question as precisely as possible, mapping the characteristics of the child against criteria in such a way that the diagnosis makes sense to parents in terms of the child they know, and leads them to a better understanding and more appropriate services. Diagnosis within these disorders is potentially especially transparent to parents because it does not depend on technically abstruse tests, but allows parents to follow and contribute to the diagnostic argument as the child's past and present behaviours begin to fall into place as being representative of specific criteria.

However, it is not always possible to give a clear cut diagnosis of the child's exact place within the pervasive developmental disorders; and this puts both parents and child in a difficult position. Nowadays we seldom hear the phrase "autistic tendencies", which was disliked for its vagueness by parents and specialists alike; but, ironically, many now complain of the vagueness of "autistic spectrum disorder" (ASD), wanting a more precise and less inclusive understanding of their child's condition. ASD tends to be used much more inclusively than "pervasive developmental disorder (PDD) not otherwise specified", which however, parents also find unsatisfactory, if sometimes necessary. "Non-specific PDD" is not only cumbersome for parents, but leaves them in the limbo of atypicality. For a child (or adult) to be atypical of the better known conditions can in practice reduce the understanding of the profes- sionals serving him, and thus restrict access to appropriate educational and other support.

The proposal of pathological demand avoidance syndrome (PDA) as a separate pervasive developmental disorder emerged from two clinics led by EN, and was certainly influenced by awareness of the practical consequences of diagnosis. Under a postgraduate training umbrella, a clinic that mainly specialised in noncommunicating children was established in the Child Development Research Unit at the University of Nottingham from 1970 to 1994, when it was reincarnated as the Early Years Diagnostic Centre and recognised as a "provider" by the NHS. The children referred for diagnostic assessment tended to be a little "puzzling" or atypical in some way: hence their referral to a specialist clinic. The training role of the university clinic made us perhaps particularly thorough in setting out the "diagnostic argument" clearly in reports, rather than relying on clinical impressions. Thus history and clinical observations were combined into an extended description of each child, and a "best fit" achieved using fully stated criteria. The result was a very detailed database, invaluable for long term research.

During the 1970s we saw a number of children who "reminded" their medical referrers of autism, but were clearly not typical of autism. Sometimes autism was rejected or questioned because of the child's imaginative ability, especially in non-echolalic role play; often the child seemed unusually sociable, though in an "odd" way, and language development was atypical of autism and less pragmatically disordered than in Asperger's syndrome. We, like others, were diagnosing these children as having atypical autism (stating in what way it was atypical); and we were not alone in being disbelieved by parents when they met children diagnosed as autistic, nor in having our diagnosis undermined by teachers who did not recognise any autistic connection.

Aware of the unsatisfactory nature of the "atypical autism" label, we also began to notice that $\mathrm{B}$ reminded us of $\mathrm{A}$, who also had something in common with C. After six years we had a cohort of 21 children who were "atypically autistic" but were also typical of each other. Not least unusual about them (as an "autistic" group) was the sex ratio: 15 of them were girls. Obviously sex ratios cannot be trusted where small numbers are involved, and these proportions equalised as we

Abbreviations: ASD, autistic spectum disorder; PDA, pathological demand avoidance syndrome; PDD, pervasive developmental disorder 
reached 150 cases (75 male, 75 female); they remain highly significantly different from sex ratios in autism.

An analysis was made, distinguishing features which all 21 children in this first cohort shared from those which were frequent but not invariable. ${ }^{12}$ Some which were expected to be merely background features turned out to be held in common more than we had realised: notably symbolic play (especially doll play and role play), and at least "soft" neurological signs. The central salient characteristic of all 21, which made them strikingly difficult for their parents and teachers, was an obsessional avoidance of the ordinary demands of life coupled with a degree of sociability that allowed social manipulation as a major skill. Despite our reluctance to use the word "manipulative" in speaking of children, it was impossible not to recognise this shared quality, especially as it contrasted so clearly with autistic children.

A name for this "different" pervasive developmental disorder seemed essential, for the usual reasons of easy referral and agreed meaning, but especially in order to be descriptive. ${ }^{3}$ Pathological demand avoidance syndrome was chosen (admittedly under pressure from an impending paediatric lecture), and now has wide recognition as a clinically useful concept. Despite the criticisms that can be made, this name has the major advantage that when doctors, psychologists, and teachers encounter the truly pathological degree of "demand avoidance" that the condition always involves on a long term basis, they are increasingly likely to consider the diagnosis, rather than blame parents or child for "unsocialised" behaviour. This has already saved some families years of bewilderment, through earlier recognition. With a name and a criterial structure, we were able to rediagnose earlier children; and parents would confess, after perhaps five years: "Autism never made sense to us; this is the first time a diagnosis has made sense".

An equally important reason for needing the separate diagnostic term proved to be the different needs of the child with PDA. Specialist schools for "autistic" children, which include one or two with PDA, immediately discover the enormous difficulties posed by a child who is deeply threatened by educational demands and organisational rules. The guidelines that are successful with autistic children need major adaptations for PDA children if any progress is to be made; these children hate routine and thrive best on novelty and variety. If perceived as ASD children, the wrong advice will be given: PDA children suffer a high exclusion rate if educated on autistic guidelines, as do young adults. This must be a powerful reason for a differential diagnosis, especially once we are able to articulate guidelines which are positively helpful for children with PDA.

\section{PARAMETERS OF COHORT}

The information presented here is based on a total cohort of 150 children diagnosed consecutively as having PDA in the two clinics headed by EN between 1975 and 2000. A few children whose clinical picture is less certain, often because of additional autistic characteristics, but atypical of autism also, were excluded. IQ in these children tends to be meaningless because of the severe demand avoidance, and alternative descriptive gauges of ability are used clinically. Age at diagnosis varied between 4 and 16 years.

Within this cohort, two separate samples were taken for specific investigation of particular topics. Fifty children with a clear cut diagnosis of PDA were chosen randomly from those seen between 1987 and 1996, comprising 28 boys and 22 girls, in order to make a discriminant functions analysis between this group and two other comparison groups: 20 children with classical autism and 20 with Asperger's syndrome. This study had the advantage that all 90 children were diagnosed in the same clinic using the same methods, and therefore had comparable data available.
The opportunity was also taken with this PDA sample to revisit data relevant to the defining criteria..$^{4-6}$ To test the long term robustness of the criteria, a further sample of 18 young people aged 16-32 years from the early stages of the PDA cohort ( 13 female, 5 male) was the subject of a follow up study looking at outcomes in early adult life, data being obtained by postal survey of parents. ${ }^{78}$ In quoting data from these investigations, we will refer to the discriminant functions analysis as study A, the criterial evidence from the same sample as study $\mathrm{B}$, and the outcomes sample of adults as study C.

Each of these studies could, of course, generate a separate paper; for conciseness, therefore, we concentrate here on the criterial data, including outcomes. A discussion of the context of PDA, together with the main results of the discriminant functions analysis, will be found on the $A D C$ website (www.archdischild.com); a brief summary of the educational guidelines will also be found on this website, while a more substantial account ${ }^{9}$ is available at www.pdacontact.org.uk or from the correspondent.

Table 1 shows defining characteristics for PDA, each including brief examples of the varied ways in which these may be manifested. Clearly no child will manifest every behavioural example; but every child with clear cut PDA will show the complexity of the overall pattern, rather than just a couple of the characteristics.

\section{SPECIFIC FINDINGS}

Percentages in study B are quoted for convenience.

\section{Passive early history}

In the study B sample of 50,78\% showed extreme passivity as described, and a further $10 \%$ were placid but not passive. Only $12 \%$ were active in some way in the first year; for example, actively protesting or (occasionally) playing. Forty four per cent (overlapping) were limp handed with toys, did not reach for them, and could not be persuaded into toy involvement.

\section{Continues to avoid and resist ordinary demands}

This was the major presenting feature in 100\% (studies A and B), and in the total sample of 150. All were also socially manipulative to this end, with one exception who was not considered manipulative when seen at 5.5 years, but was definitely so by 6.9 years. Socially manipulative avoidance is now considered essential to the diagnosis. Most have a variety of avoidance strategies; many have more than 10 .

Of the 18 adults followed up (study C), all were still very demand avoidant: eight "about the same" as in childhood, three more than formerly, and seven less than formerly. Half were still unequivocally described as socially manipulative, eight as somewhat socially manipulative, and only one as no longer manipulative (he would just say "I can't"). Out of a range of nine suggested types of avoidance strategies, 15 used more than two types, 10 used five or more types, and two used all nine.

\section{Surface sociability, but lack of sense of identity, pride, or shame}

All give an impression of sociability, but $84 \%$ show very inappropriate behaviour and social response over and above their demand avoidance. Sixty eight per cent show aggression to others, with no sex difference; $60 \%$ have extreme outbursts or panic attacks. Eighty two per cent show little sense of status or identity in others, and $86 \%$ show no sense of pride, shame, responsibility, or identity in themselves, in addition to the lack of this sense which is implied by their demand avoidance. Among the adults, 14 of the 18 can be violent when angry, and five of these are judged by their parents to be capable of "badly hurting someone"; seven have threatened suicide, and two of these have attempted it. Five of these respondents are afraid of their child, and 16 are afraid for her. One adult has "no sense of right or wrong", and in seven cases parents are "uncertain" 
Table 1 Defining criteria for diagnosis of pathological demand avoidance syndrome (with descriptive notes and comparison with autism)

\begin{tabular}{|c|}
\hline \\
\hline $\begin{array}{l}\text { 1. Passive early history in first year: Often doesn't reach, drops toys, "just watches"; often } \\
\text { delayed milestones. As more is expected, child becomes "actively passive", i.e. strongly objects to } \\
\text { normal demands, resists. A few actively resist from the start, everything is on own terms. Parents } \\
\text { tend to adapt so completely that they are unprepared for the extent of failure once child is } \\
\text { subjected to ordinary group demands of nursery or school; they realise child needs "velvet gloves" } \\
\text { but don't perceive this as abnormal. Professionals too see child as puzzling but normal at first. } \\
\text { 2. Continues to resist and avoid ordinary demands of life: Seems to feel under intolerable } \\
\text { pressure from normal expectations; devotes self to actively avoiding these. Demand avoidance may } \\
\text { seem the greatest social and cognitive skill, and most obsessional preoccupation. As language } \\
\text { develops, strategies of avoidance are essentially socially manipulative, often adapted to } \\
\text { adult involved; they may include: *Distracting adult: "Look out of the window!", "I've got you a } \\
\text { flower!", "I love your necklace!", "I'm going to be sick", "Bollocks! -I said bollocks!" } \\
\text { "Acknowledging demand but excusing self. "I'm sorry, but I can't", "I'm afraid I've got to do this } \\
\text { first", "I'd rather do this", "I don't have to, you can't make me", "you do it, and I'll ...", "Mummy } \\
\text { wouldn't like me to". *Physically incapacitating self: hides under table, curls up in corner, goes } \\
\text { limp, dissolves in tears, drops everything, seems unable to look in direction of task (though retains } \\
\text { eye contact), removes clothes or glasses, "I'm too hot", "I'm too tired", "It's too late now", "I'm } \\
\text { handicapped", "I'm going blind/deaf/spastic", "My hands have gone flat". *Withdrawing into } \\
\text { fantasy, doll play, animal play: talks only to doll or to inanimate objects; appeals to doll, "My girls } \\
\text { won't let me do that", "My teddy doesn't like this game"; "But I'm a tractor, tractors don't have } \\
\text { hands"; growls, bites. *Reducing meaningful conversation: bombards adult with speech (or other } \\
\text { noises, e.g. humming) to drown out demands; mimics purposefully; refuses to speak. * (As last } \\
\text { resort): outbursts, screaming, hitting, kicking; best construed as panic attack. }\end{array}$ \\
\hline
\end{tabular}

Autistic/Asperger's children

Seems more abnormal much earlier; lack of social response and lack of empathy alert parents, together with poor body language and stereotypic behaviour.

normal demands, resists. A few actively resist from the start, everything is on own terms. Parents

Can be reluctant, but ignores or shuts out pressure in a non-social way, without acknowledging others' needs. Has very few conscious strategies for avoidance. Doesn't adapt particular strategy for particular person. Doesn't have enough empathy to make excuses, and usually not enough empathic language either. Direct, not devious.

resort): Outbursts, screaming, hitting, kicking; best construed as panic attack.

3. Surface sociability, but apparent lack of sense of social identity, pride, or shame: At first Because of lack of social empathy, autistic children sight normally sociable with enough empathy to manipulate adults as shown above; but ambiguous (even Asperger's children) don't purposefully and without depth. No negotiation with other children, doesn't identify with children as a category: manipulate, though people around them may feel the question "Does she know she's a child?" makes sense to parents, who recognise this as a major problem. Wants other children to admire, but usually shocks them by complete lack of boundaries. No sense of responsibility, not concerned with what is "fitting to her age" (might pick fight with toddler). Despite social awareness, behaviour is uninhibited, e.g. unprovoked aggression, extreme giggling/inappropriate laughter, or kicking/screaming in shop or classroom. Prefers adults but doesn't recognise their status. Seems very naughty, but parents say "not naughty but confused" and "it's not that she can't or won't, but she can't help won't" - parents at a loss, as are others. Praise, reward, reproof, and punishment ineffective; behavioural approaches fail. 4. Lability of mood, impulsive, led by need to control: Switches from cuddling to thumping for Autistic children are seldom impulsive; they work to no obvious reason; or both at once "I hate you" while hugging, nipping while handholding) Very (their own) rules, and parents learn what will upset impetuous, has to follow impulse. Switching of mood may be response to perceived pressure; goes "over the top" in protest or in fear reaction, or even in affection; emotions may seem like an "act". Activity must be on child's terms; can change mind in an instant if suspects someone else is exerting control. May apologise but reoffend at once, or totally deny the obvious. Teachers need great variety of strategies, not rule based: novelty helps.

5. Comfortable in role play and pretending: Some appear to lose touch with reality. May take over second-hand roles as a convenient "way of being", i.e. coping strategy. Many behave to other children like the teacher (thus seem bossy); may mimic and extend styles to suit mood, or to control events or people. Parents often confused about "who he really is". May take charge of assessment in role of psychologist, or using puppets, which helps cooperation; may adopt style of baby, or of video character. Role play of "good person" may help in school, but may divert attention from underachievement. Enjoys dolls/toy animals/domestic play. Copes with normal conventions of shared pretending. Indirect instruction helps.

6. Language delay, seems result of passivity: Good degree of catch-up, often sudden. Pragmatics not deeply disordered, good eye contact (sometimes over strong); social timing fair except when interrupted by avoidance; facial expression usually normal or over vivacious. However, speech content usually odd or bizarre, even discounting demand-avoidant speech. Social mimicry more common than video mimicry; brief echoing in some. Repetitive questions used for distraction, but may signal panic.

7. Obsessive behaviour: Much or most of the behaviour described is carried out in an obsessive way, especially demand avoidance: as a result, most children show very low level achievement in school because motivation to avoid demands is so sustained, and because the child knows no boundaries to avoidance. Other obsessions tend to be social, i.e. to do with people and their characteristics; some obsessionally blame or harass people they don't like, or are overpowering in their liking for certain people; children may target other individual children.

8. Neurological involvement: Soft neurological signs are seen in the form of clumsiness and physical awkwardness; crawling late or absent in more than half. Some have absences, fits, manipulated by the situation or by fate. They give no impression of sociability, except with questions or statements about their preoccupying interests from verbal children. They may become more sociable in ime, but seldom develop real (natural) social empathy.

(their own) rules, and parents learn what will upset hem. They do not put on an act for someone else until very much older, if then. Rules, routine and predictability help.

Inflexibility, lack of symbolic and imaginative play and lack of empathy all make it very difficult for autistic children to pretend (other than by arranging miniature objects), or to take roles more fully than by simple echoing - though Asperger's children may learn "scripted" roles, with difficulty and without fluency. Indirectness confuses.

Language is both delayed and deviant, non-existent in many. Even Asperger's children show very disordered pragmatics of language, poor eye contact and social timing, little facial expression or gesture.

Autistic children are also obsessive, but less so with social topics. They are not obsessively focused on demand avoidance, and do not use obsessions for manipulative purposes. Order, arrangements and perceptual fascinations.

Some comparable involvement in autism; less in terms of crawling and episodic dyscontrol. episodic dyscontrol, or generalised excitability. Not enough hard evidence as yet.

whether the individual has a sense of right or wrong; this represents an improvement over earlier fears, since parents at diagnosis usually felt despairing as to whether they could teach their child right from wrong.

\section{Lability of mood, impulsive, led by need to control}

Sixty eight per cent of the sample in studies A and B showed extreme lability of mood, and among these $30 \%$ included a switching from "love" to "hate" in their behaviour. At an apparently trivial level, the child may repeatedly invite the mother's suggestions, only to scream rejection and reassert control: any suggestion from someone else can be perceived as intolerably demanding. Need to control is the other side of the demand avoidance coin, and the more actively avoidant or aggressive children are often described in this way.

Among the adult sample, parents were able to differentiate between impulsivity and lability of mood. Fourteen adults were both impulsive in behaviour and prone to mood swings, 12 of these individuals being capable of violence when angry. Two had mood swings but were not impulsive (of whom both could be violent). One was impulsive without mood swings, and one was neither; these two were not violent to others, but both could be self-injurious. It seems that lability and impulsivity are lasting risks, though not necessarily appearing in every child; there may be neurological implications. 


\section{Comfortable in role play and pretending}

This feature is often the reason for a child having received no diagnosis at all, despite major problems, because of its contraindication to autism; the few children showing neither role play nor general symbolic play are younger, and are likely to develop it later (though we have a recent child of 3 who only responds to demands via role play). Ninety per cent of the PDA children in studies A and B had general symbolic play (excluding role play); $64 \%$ had "lots of" role play, and a further $22 \%$ had some role play. Thirty four per cent of the sample confused reality and pretending; among the role play children, $32 \%$ of the whole sample were at their most animated, comfortable or competent when in role (as observed in the clinic). Some regularly talk to specific inanimate objects (for example, mother: "She has better conversations with the cups on the dresser than she does with $\left.m^{\prime \prime}\right)$. Tape recorded examples of such conversations show that they are not echolalic in nature.

Still more interesting is the robustness of this feature as it survives in adulthood; only three of the 18 adults in study C did not show any of the nine types of fantasy activity listed in the survey, and all of these were male. Five showed six or more types. Ten seemed to lose touch with reality through fantasy. Seven mimicked other people's roles from video, and seven from real life; four mimicked odd or violent behaviour. Of the "real life" role mimics, three took this to extremes so that it was "hard to know who she really is". Seven put on an act within their own general identity, four acted out self generated stories or scripts, and four would actually record an act or role on video, audiotape, or photos in an obsessive manner. Six engaged in fantasy communications such as poison pen letters, fantasy love letters, hoax phone calls and letters, false accusations to the police, and obscene stories.

\section{Language delay, seems result of passivity}

Ninety per cent (study B) showed speech delay and most had had speech therapy contact, which therapists themselves usually described as difficult and ineffective because of demand avoidance; typically, they seem to catch up independently of speech therapy, the great majority by the age of 6 years. In about one in four of cases we had no note of social timing or facial expression, suggesting that it was normal, but $66 \%$ were noted as having normal social timing when engaged, and 52\% as having normal or over vivacious facial expression. However, speech content was judged as abnormal in $86 \%$, including being "over the top" or bizarre. Additionally 26\% had used jargon; $44 \%$ had had a period of non-social echolalia, usually brief; $26 \%$ showed semi-social mimicry (mainly acting out videos or story characters); and $46 \%$ showed social mimicry ("becoming" the teacher, mother, or psychologist and thereby taking control of situations). In adults, the amount of fantasy persisting ensures that most will continue to have abnormal content in their language.

\section{Obsessional behaviour}

The "pathological" nature of the demand avoidance means that it always has obsessional force; but role play is the second major obsession, which gives the impression of more socially oriented obsessions in PDA than in autism/Asperger's syndrome. This is borne out by the adults. Seventeen of the 18 are described as obsessively demand avoidant (the other being described as "not obsessively so at the moment"), and 10 use other obsessions as an avoidance strategy or distraction. Twelve have obsessions about specific people, 11 blame, target, or harass specific people, six want to be with specific people (obsessionally), and four want to be a specific person or character. Interestingly, 10 have contradictory obsessions, especially over-cleanliness/slovenliness. All these obsessional interests may also be seen in childhood, especially harassment.

\section{Neurological involvement}

This aspect of the condition is under-researched to date, but there is certainly coexistent epilepsy in some, and evidence of absence or of episodic dyscontrol may be seen. Some were medically described as "floppy" in infancy, but this may have been the limpness of passivity; movement later tends be clumsy and over-determined on the whole. Forty one per cent are known to have achieved sitting late ( 8 months or later); $28 \%$ are known to have crawled at 11 months or later, and a further $28 \%$ are known not to have crawled at all (while one child crawled "only when she thought no one was looking"!). Fifty per cent are known to have walked at 15 months or later (study B). Many of the children have been described as "flitting" in attention, especially in school; however, observation shows that $48 \%$ (study B) are definitely not flitting in hyperactive terms, and that $34 \%$ only show this behaviour when demands are being made on them. Half of this group concentrate well when engaged in self-chosen interests (mainly dolls and video). Only $4 \%$ are hyperactive under whatever conditions they are observed.

\section{CONCLUSIONS}

This clinical description of "pathological demand avoidance syndrome" (PDA), conceptualised as a separate entity within the pervasive developmental disorders, has already been found clinically useful by many paediatricians, psychiatrists, and psychologists in diagnosing a group of children otherwise seen as puzzling and atypical in relation to the autistic spectrum. It gives "specific" status to a large proportion of those children (and adults) who would earlier have been diagnosed as having "pervasive developmental disorder not otherwise specified" (PDDnos). Figure l sets PDA in the context of the whole family of pervasive developmental disorders, and is explained as follows:

- The diagram shows clusters of symptoms (syndromes) which make up specific disorders within the "family". These will vary in mildness or severity, and intellectual ability will make a significant difference (as in any disability); so will underlying personality.

- Occasionally a child will show a cluster of symptoms that falls between these typical clusters. This is described as non-specific pervasive developmental disorder. However, sometimes this child will more clearly belong to a typical cluster as time goes on and particular symptoms take on greater prominence.

- In every case, the child or adult has difficulty in coding or making sense of a particular area of communicative life where we usually regard "making sense" as biologically normal. This is not necessarily in terms of spoken language, but may be about the non-verbal ways in which we understand each other, such as meanings and intentions, or identity and obligation.

- None of these children chooses to be the way they are. These are biological, sometimes genetic, disorders. However difficult the behaviour arising from them, the child is not wilfully being naughty, and cannot easily behave differently; though we may be able to help him or her to improve over time. None of these conditions has an emotional cause, although any might make the child behave emotionally, especially if misunderstood.

- Differential diagnosis has practical implications. Each of these disorders has its own guidelines for education and management, which have different emphases. Some guidelines suitable for one condition may be very unhelpful for another. This is why accurate diagnosis is important. Specific educational management is essential in all cases, having regard also to individuality.

- In Asperger's syndrome, the child usually becomes increasingly aware of his or her difficulties as he or she moves into 
THE "FAMILY" OF PERVASIVE DEVELOPMENTAL DISORDERS

(sometimes "autistic spectrum" is loosely used to describe the whole family)

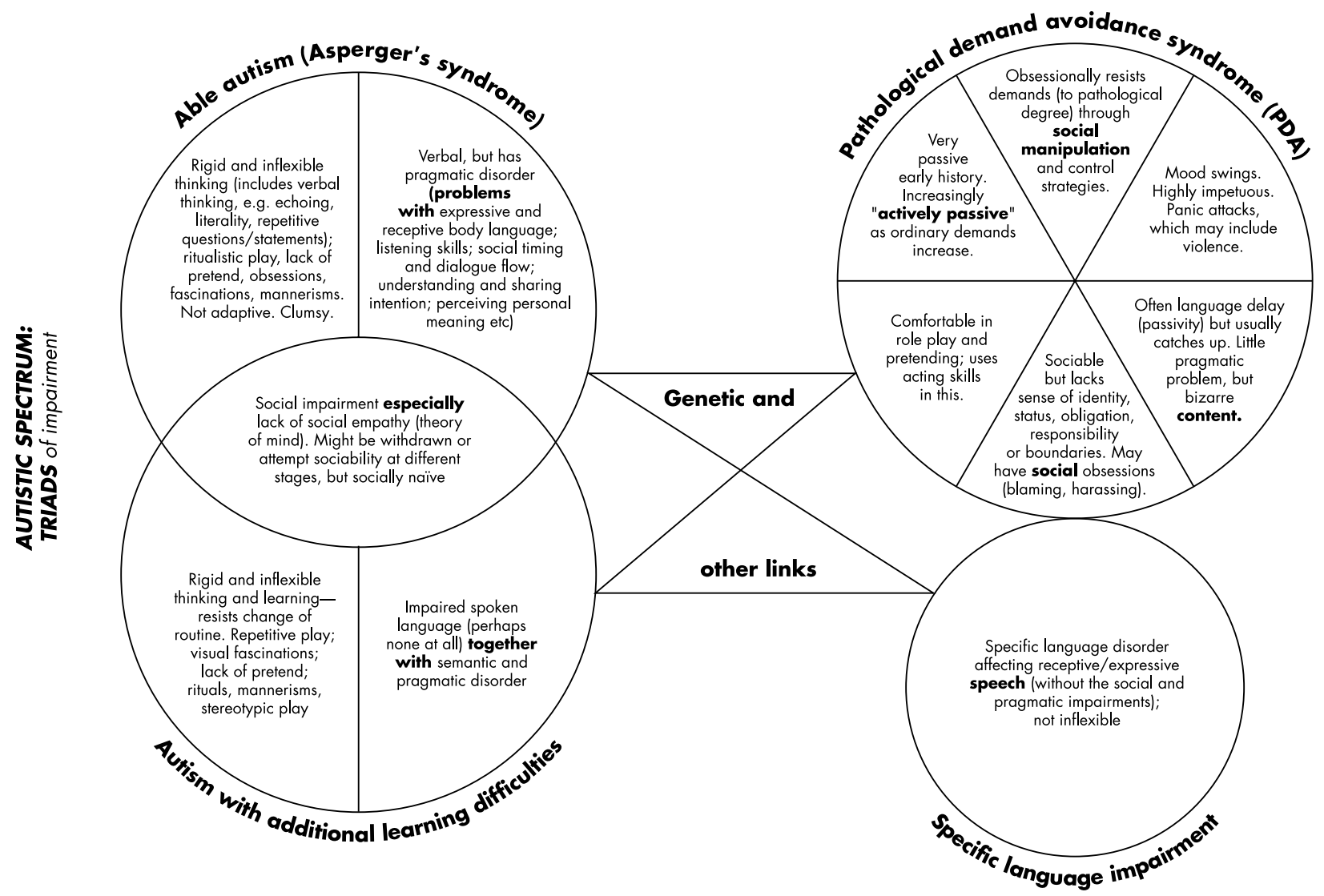

Figure 1 The "family" of pervasive developmental disorders.

adolescence. This, combined with an increasing wish for friends (often unfulfilled) may lead to clinical depression, and a need for informed and sensitive counselling.

The descriptive criteria, first produced in 1988 from clinical notes before the statistical studies had been undertaken, remain surprisingly robust, both between children and, equally important, from childhood to adulthood. They were revised in 1995, with very little change except to include language delay, and finally revised for this paper to take account of the statistical studies quoted in the notes; even so, changes have been more in terms of organisation of the criterial concepts (to make stating of the "diagnostic argument" easier for clinicians), rather than changing the concepts themselves. There have been slight changes of emphasis here and there to follow statistical data.

The "recognition factor" for these criteria is striking, both by parents whose child has previously had an "atypical autism" diagnosis, and by those whose children have been seen as extraordinarily difficult and "odd", but not diagnosable. Repeatedly, parents say that "the notes might have been written just about my child", often when they had thought their child to be "a complete one-off", and even been told this by professionals. Medical and psychological professionals also experience this strong recognition factor when they compare individual puzzling children with the defining criteria; a typical example (from a principal psychologist's letter) was: "School were amazed that anyone could describe this 5 year old as accurately as this without seeing him". The recognition factor seems to attest to how closely PDA hangs together as an entity. Clearly, "hanging together as an entity" is not enough if that entity is not significantly different from both autism and Asperger's syndrome, either separately or apart, and this is evidenced by the very high significance levels yielded by discriminant functions analysis on a wide range of variables (see website).

The other statistical studies help to identify which criterial aspects are most significant for diagnosis. Clearly, demand avoidance using social manipulation is crucial, applying to $100 \%$ of cases, and differing strongly from autistic spectrum children. Lability of mood, lack of pride or shame, and strong interest in role play and pretending are all highly important features which in practice make children especially difficult to teach and adults hard to provide for. The violence seen in harassment obsessions, while not obvious in all children, is of concern for its persistence; no children had formerly been aggressive and then stopped.

Pathological demand avoidance is beginning to be much more widely recognised, diagnosed, and understood, because these children exist and require recognition, diagnosis, and understanding. We already have quite specific strategies to offer in managing their problems, which are very different from autism-specific strategies. The history of autism was marred by protracted clinical disbelief in the concept of autism: perhaps we should learn from that, and move more rapidly into further PDA-specific research.

Authors' affiliations

E Newson, K Le Maréchal, C David, Early Years Diagnostic Centre, 272 Longdale Lane, Ravenshead, Nottingham NG15 9AH, UK 


\section{REFERENCES}

1 Newson E. Defining criteria for diagnosis of pathological demand avoidance syndrome, with comparison to autism. Child Development Research Unit, University of Nottingham/Early Years Diagnostic Centre, Ravenshead, 1988/1995/2000

2 Newson E. Pathological demand avoidance syndrome: mapping a new entity related to autism? Inaugural lecture, University of Nottingham, 1990.

3 Barber MA, Davis PM. Fits, faints or fatal fantasy? Fabricated seizures and child abuse. Arch Dis Child 2002;86:230-3.

4 Dent K, later Le Maréchal. The classification of pervasive developmenta disorders: pathological demand avoidance syndrome. Evaluation and comparison with autism and Asperger's syndrome. Department of Psychology thesis, University of Nottingham, 1996.

5 Newson E. Pathological demand avoidance syndrome: a statistical update. In: Shattock P, Linfoot $G$, eds. Therapeutic intervention in autism: perspectives from research and practice. University of Sunderland, UK, 1996.
6 Newson E, Le Maréchal K. Pathological demand avoidance syndrome: discriminant functions analysis demonstrating its essential differences from autism and Asperger's syndrome. In: Shattock P, Linfoot $G$, eds.

Psychobiology of autism: current research and practice. University of Sunderland, UK, 1998.

7 David C. Pathological demand avoidance syndrome (PDA): what is the prognosis? Department of Psychology thesis, University of Wales, 1999.

8 Newson E, David C. Pathological demand avoidance syndrome: what is the outlook? In: Shattock P, Linfoot G, eds. From research into therapy. University of Sunderland, UK, 1999.

9 Newson E. Educational and handling guidelines for children with pathological demand avoidance syndrome (PDA). Information service, Early Years Diagnostic Centre, Nottingham NG15 9AH, 1998.

10 American Psychiatric Association. Diagnostic and statistical manual of mental disorders, 4th edition (DSM-IV). Washington, DC: APA, 1994. 